\title{
LEMBRANÇAS DE UM PERCURSO ACADÊMICO: UMA ANÁLISE SEMIÓTICA DA CONSTRUÇÃO DO ATOR DA ENUNCIAÇÃO DOS MEMORIAIS
}

\author{
Mariana Luz Pessoa de BARROS*
}

- RESUMO: O memorial acadêmico parece ser um objeto privilegiado para o exame de simulacros e valores relacionados aos modos de atuação no meio acadêmico brasileiro. Ao escrevê-lo, o professor-pesquisador reelabora seu percurso profissional e intelectual como resposta a uma exigência institucional, uma vez que, no Brasil, muitos concursos que fazem parte da carreira universitária solicitam a elaboração de um memorial acadêmico. Tendo isso em vista, estabelecemos como objetivo deste trabalho analisar a produção da imagem do enunciador-candidato dos memoriais, a partir das propostas de Discini $(2003,2015)$ e de Fiorin (2004, 2015), desenvolvidas para o tratamento do ator da enunciação no âmbito da semiótica de base greimasiana. Exemplares de diferentes áreas e faculdades da Universidade de São Paulo são comparados, o que permite a verificação de suas diferenças e de suas semelhanças quanto ao emprego de procedimentos textuais e discursivos na construção do ator da enunciação. Como resultado, depreendemos a imagem de um professor-pesquisador arrojado, inovador, competitivo e cooperativo nos memoriais das Biológicas e de um professor-pesquisador crítico, criativo e levemente desviante nos memoriais das Humanidades.

- PALAVRAS-CHAVE: memorial acadêmico; ator da enunciação; semiótica discursiva.

\section{Introdução}

Subjaz à memória uma cisão irremediável entre quem somos no agora do ato da rememoração e quem já fomos num então, supostamente rememorado. É o que nos ensina Ecléa Bosi quando, recuperando as reflexões de Halbwachs, afirma que memória é trabalho:

O caráter livre, espontâneo, quase onírico da memória é, segundo Halbwachs, excepcional. Na maior parte das vezes, lembrar não é reviver, mas refazer, reconstruir, repensar, com imagens e ideias de hoje, as

\footnotetext{
* Universidade Federal de São Carlos (UFSCar). São Carlos - SP, Brasil. maluzpessoa@gmail.com. ORCID: 0000-0002-1662-2125.
} 
experiências do passado. A memória não é sonho, é trabalho. Se assim é, deve-se duvidar da sobrevivência do passado, "tal como foi", e que se daria no inconsciente de cada sujeito. A lembrança é uma imagem construída pelos materiais que estão, agora, à nossa disposição, no conjunto de representações que povoam nossa consciência atual. Por mais nítida que nos pareça a lembrança de um fato antigo, ela não é a mesma imagem que experimentamos na infância, porque nós não somos os mesmos de então e porque nossa percepção alterou-se e, com ela, nossas ideias, nossos juízos de realidade e de valor. O simples fato de lembrar o passado, no presente, exclui a identidade entre as imagens de um e de outro, e propõe a sua diferença em termos de ponto de vista (BOSI, 1994, p. 55).

O trabalho da memória, ao qual se refere a autora, consiste nessa constante refacção da experiência primeira, com base nas experiências vividas no presente. No esforço de reconstruir um outro tempo, "exerce um papel condicionante todo o conjunto de noções presentes que, involuntariamente, nos obriga a avaliar (logo, alterar) o conteúdo das memórias" (BOSI, p. 1994, p. 55). Relaciona-se a esse trabalho de reelaboração, a noção de memória coletiva de Halbwachs, que atrela a memória do indivíduo à dos grupos aos quais pertence, e a dos grupos à da sociedade. Para o sociólogo, as lembranças ocorrem dentro de comunidades e dependem, portanto, das relações que cada indivíduo estabelece com diferentes grupos sociais. Logo, o trabalho da memória não é concebido como algo que pode ser feito por um indivíduo isolado: "lembranças permanecem coletivas e nos são lembradas por outros, ainda que trate de eventos em que somente nós estivemos envolvidos e objetos que somente nós vimos. Isso acontece porque jamais estamos sós" (HALBWACHS, 1990, p. 26). Embora não seja nossa intenção aprofundarmo-nos na discussão acerca da memória coletiva, retemos aqui alguns pontos que serão fundamentais para o modo como concebemos a construção da memória nos memoriais acadêmicos que formam o corpus de nossa pesquisa.

O memorial acadêmico, gênero que tem na memória sua força criadora, não foge às coerções do presente, ou ainda, ao trabalho realizado no tempo presente, em que se dá a narração e o processo de reconstrução do vivido. Nesse gênero, um professorpesquisador reelabora, por meio da escrita, seu percurso profissional, intelectual e acadêmico como resposta a uma exigência institucional, uma vez que, no Brasil, muitos concursos que fazem parte da carreira universitária - concurso para ingresso em uma instituição de ensino superior, concurso de livre-docência, concurso para professor titular, por exemplo - solicitam aos professores-pesquisadores a elaboração de um memorial acadêmico, que se tornará, inclusive, objeto de arguição por parte de uma banca.

Desse modo, não podemos ignorar, no momento da análise, essa situação institucional presente à qual vem responder o memorial, uma vez que encontramos, nesse gênero, um enunciador que, inserido numa comunidade acadêmica, procura 
construir para si o papel temático de professor-pesquisador e ainda a imagem de competência para a pesquisa e para o ensino, afinal, está em busca da aprovação da banca do concurso para o qual o texto foi redigido e, por meio dela, da aprovação dessa comunidade. Precisamos, portanto, ter em mente que os memoriais não apresentam apenas o trabalho de uma memória individual, mas nos deixam apreender uma dimensão coletiva de reelaboração do passado. Isso significa afirmar que aquilo que é lembrado e esquecido correlaciona-se aos diferentes grupos dos quais cada memorialista participa e, dentre esses grupos, encontram-se, conforme já dissemos, aqueles ligados à vida acadêmica.

Partindo dessas reflexões, estabelecemos como objetivo deste trabalho depreender a imagem do professor-pesquisador projetada pelos memoriais acadêmicos, por meio do exame de um corpus de 26 memoriais, produzidos a partir de 1990 na Faculdade de Educação; no Curso de Letras (FFLCH); na Faculdade de Medicina; e no Instituto de Biociências (todos da USP). Apesar de ainda pouco explorado pelos estudiosos do texto e do discurso ${ }^{1}$, o memorial, pelas razões já elencadas, parece constituir objeto privilegiado para o exame de simulacros e valores relacionados aos modos de fazer e de ser, e, assim, também de lembrar e esquecer, que circulam no meio acadêmico brasileiro. Afinal, examinar esse gênero não corresponde somente a direcionar o olhar para cada memória individual, mas a entendê-la como parte de uma coletividade e ainda como parte de uma memória acadêmica, colocada em circulação por meio da linguagem. Como afirma Bosi (1994, p. 56): “O instrumento decisivamente socializador da memória é a linguagem [...]. Os dados coletivos que a língua sempre traz em si entram até mesmo no sonho (situação-limite da pureza individual)".

O material a ser analisado foi selecionado a partir de uma leitura inicial de um grande número de memoriais para que pudéssemos identificar algumas características gerais de cada grande área (Humanas e Biológicas) e ainda de cada curso, faculdade ou instituto. Só então foi feita a escolha dos exemplares que seriam examinados com maior acuidade e que comporiam de fato o corpus da pesquisa que aqui apresentamos, por trazerem, de forma exemplar, essas características que nos pareceram mais partilhadas por cada grande área.

Para dar conta do exame da imagem do enunciador projetada nos memoriais, temos como base as propostas de Discini $(2003,2015)$ e de Fiorin $(2004,2015)$ que, no âmbito da semiótica discursiva, lançam novo olhar sobre a noção aristotélica de éthos, compreendendo-o a partir do conceito de ator da enunciação. Segundo Benveniste (1995), a enunciação, ao colocar a língua em funcionamento por um ato individual de utilização, instaura o eu, aquele que diz eu, e o tu, aquele a quem se dirige o eu. $\mathrm{Na}$ semiótica, o eu e o tu são entendidos como actantes, posições enunciativas geradas

Dentre os interessados pelo gênero, destacamos o Grupo Interdisciplinar de Pesquisa, Formação, (Auto)Biografia e Representações (GRIFAR) da Universidade Federal do Rio Grande do Norte, vinculado ao programa de Pós-Graduação em Educação da mesma Universidade, cujos membros têm sido responsáveis por um volume importante de publicações de artigos e livros dedicados ao memorial acadêmico, entre outros gêneros. 
por uma sintaxe do discurso, e tornam-se atores da enunciação ao receberem um revestimento semântico. Como nos mostra Fiorin (2004, p. 18):

Quando falamos em "eu" e "tu", falamos em actantes da enunciação, ou seja, em posições dentro da cena enunciativa, aquele que fala e aquele com quem se fala. No entanto, nos diferentes textos, essas posições são concretizadas e esses actantes tornam-se atores da enunciação. $\mathrm{O}$ ator é uma concretização temático-figurativa do actante.

O semioticista aponta ainda para o fato de que a análise do ator da enunciação se realiza não pela busca do autor de carne e osso, mas do autor discursivo, apreendido com base nas marcas deixadas no enunciado que permitem a reconstrução da imagem do enunciador. Conforme lemos em Greimas e Courtès (2008, p. 18):

Do ponto de vista da produção do discurso, poder-se-á distinguir o actante da enunciação, que é um actante logicamente implícito, logicamente pressuposto pelo enunciado, do ator da enunciação: nesse último caso, o ator será por exemplo "Baudelaire", na medida em que se define pela totalidade de seus discursos.

Sem se furtar ao diálogo com outros teóricos do discurso e do texto, especialmente com Maingueneau (1995), que define o éthos como caráter, corpo e voz (o tom) do enunciador, Discini $(2003,2015)$ entende-o como um modo de ser e habitar o mundo, depreendido de uma totalidade discursiva enquanto imagem do enunciador. Ao conceber o éthos como aquilo que é produzido pelas recorrências de um modo próprio de dizer, a autora aproxima-o da noção de estilo, uma vez que é, justamente, por meio da análise do estilo que se chega à apreensão desse simulacro discursivo. Logo, compreende-se o estilo como:

Modo de presença de um sujeito dado no ato de enunciar pressuposto a uma totalidade de enunciados, remete a um sujeito discursivo, que deixa rastros de sua identidade naquilo que diz, por meio de um modo próprio de dizer, o que supõe peculiaridades éticas e afetivas na relação com o mundo (DISCINI, 2015, p. 87).

A partir disso, é possível pensar o éthos como um "sujeito de estilo", que "traz à luz a categoria discursiva de pessoa sintaticamente pressuposta a uma totalidade, bem como semântica e intensivamente "encarnada"” (DISCINI, 2015, p. 87).

A investigação do ator da enunciação dos memoriais terá como base a teoria semiótica de vertente greimasiana e seus desenvolvimentos atuais. Para examinar sua construção, é necessário passar por todos os níveis do percurso gerativo do sentido, modelo teórico elaborado pela semiótica para o estudo da significação no plano do 
conteúdo. Tal percurso divide-se em níveis, que são orientados do mais simples e abstrato ao mais complexo e concreto: nível fundamental (em que se estabelece uma oposição semântica mínima), nível narrativo (em que a narrativa é organizada do ponto de vista de um sujeito) e nível discursivo (em que a narrativa é assumida pelo sujeito da enunciação). Neste trabalho, será enfatizada a análise do nível discursivo e ainda da textualização.

Todos os níveis do percurso encontram-se metodologicamente estruturados em uma sintaxe e uma semântica, o nível discursivo não foge à regra. $\mathrm{O}$ estudo da sintaxe discursiva, que consiste na descrição dos mecanismos de discursivização (actorialização, temporalização, espacialização), permite observar os efeitos de sentido de aproximação e de distanciamento, de subjetividade e de objetividade, entre outros, produzidos no enunciado e que interferem diretamente na relação entre os parceiros da comunicação (enunciador e enunciatário) e, assim, na imagem projetado pelo professor-pesquisador. A obra As astúcias da enunciação, de José Luiz Fiorin (1996), será a base principal dessa etapa do trabalho.

Já o exame da semântica discursiva mostra-se pertinente, pois concerne aos dois níveis de concretização do sentido - a tematização e a figurativização - que conferem revestimento sensorial e ideológico ao ator candidato. Os valores assumidos por um sujeito, no nível narrativo, aparecem como temas, no nível discursivo. Os temas, então, revestem os esquemas narrativos e as figuras podem ou não revestir os temas. Barros (2002, p. 116-117) mostra que os temas classificam e organizam a realidade significante e as figuras particularizam e concretizam os discursos temáticos e abstratos, ao estabelecerem a relação intersemiótica entre mundo natural (visto como uma semiótica) e língua. O qualificativo figurativo é definido por Greimas e Courtés (2008, p. 187-188), no Dicionário de semiótica, como "um conteúdo dado (de uma língua natural, por exemplo) quando este tem um correspondente no nível da expressão da semiótica natural (ou do mundo natural)". É, então, por meio da semântica discursiva que se tem acesso à dimensão mais sensorial do texto e também, como mostra Fiorin (1998), em Linguagem e ideologia, às suas determinações sociais. A sintaxe discursiva é o campo da manipulação mais consciente e a semântica, com a tematização e a figurativização, o campo das determinações inconscientes e, portanto, o das determinações ideológicas.

Por fim, a textualização é entendida como "uma parada desse percurso [o percurso gerativo do sentido] num momento qualquer do processo e um desvio em direção à manifestação" (GREIMAS; COURTÉS, 2008, p. 504), logo, diz respeito à semiose, ao encontro do plano de conteúdo, cujo simulacro, conforme já dissemos, é estabelecido pelo percurso gerativo de sentido, e do plano de expressão. Recursos como a pontuação, a organização dos parágrafos, a estruturação dos capítulos, entre outros, serão entendidos, portanto, como parte da textualização. Também teceremos breves comentários acerca da edição dos memoriais, sem perder de vista a questão central de nossa pesquisa: a produção da imagem do enunciador. Conforme mostra Fiorin (2004, p.21), trata-se de abordagem pertinente para investigar a construção desse ator da enunciação: 
Onde se encontram, na materialidade discursiva da totalidade, as marcas do éthos do enunciador? Dentro dessa totalidade, procuram-se recorrências em qualquer elemento composicional do discurso ou do texto: na escolha do assunto, na construção das personagens, nos gêneros escolhidos, no nível de linguagem usado, no ritmo, na figurativização, na escolha dos temas, nas isotopias etc. Num jornal, a imagem do enunciador se mostra até mesmo no tamanho das letras utilizadas, no número de colunas ocupadas pela manchete e assim por diante.

É preciso dizer ainda que os gêneros autobiográficos possuem certas especificidades com relação ao exame do éthos, conforme mostraremos a seguir. Como é comum em autobiografias, nos memoriais analisados, um narrador "em primeira pessoa", instalado no presente, relata o que teria sido o seu passado. Isso significa que o narrador e o ator do narrado são instalados no texto por meio de debreagens enunciativas de pessoa (FIORIN, 1996), assim temos dois "eus" projetados, o que narra, num aqui e agora, e aquele que "vive" a história narrada, num lá e então. É o que vemos no excerto apresentado a seguir, em que verbos como "convivi" referem-se à experiência do ator do narrado no passado, enquanto "trago" diz respeito ao presente do narrador: "Nasci numa fazenda de café e desde cedo convivi com o cheiro dos grãos de café secando no terreiro - trago este aroma em minha mente até hoje [...]" (ANGYALOSSY, 2006, p. 1, grifo nosso). O uso da primeira pessoa para se referir a esses dois sujeitos é um dos recursos da sintaxe discursiva ${ }^{2}$ que contribuem para criar a identificação entre ator central e narrador, própria das autobiografias ${ }^{3}$.

Nas autobiografias também se produz, geralmente, o efeito de identificação entre o narrador e o enunciador, que nos memoriais em questão se dá por meio de embreagens que fazem com que o narrador se apresente como o "autor" do texto, como em: "Como escrevi anteriormente, aprendemos juntos, pois o mundo das plantas é um aprendizado contínuo - não há barreiras, não há fim" (ANGYALOSSY, 2006, p. 5). A assinatura que encontramos no final de muitos memoriais é outro elemento que contribui para isso: quem assina é o narrador ou o enunciador? Logo, a assinatura também resulta de uma embreagem, entendida como uma neutralização das oposições que constituem as categorias de pessoa, tempo e espaço. Nesses exemplos, ocorre um tipo de embreagem que confunde os níveis do narrador e do enunciador, instância pressuposta, criando a aproximação entre eles (FIORIN, 1996).

\footnotetext{
Lembramos aqui que a sintaxe discursiva consiste, na semiótica, nessa projeção de pessoas, tempos e espaços no enunciado.

3 Segundo Lejeune (1996), a relação de identidade entre autor e narrador, narrador e personagem central, personagem central e autor é um dos elementos que fundam o pacto autobiográfico. Neste trabalho, utilizamos a metalinguagem da semiótica e falamos, portanto, em ator central do narrado, narrador e enunciador. De modo breve, podemos afirmar que o enunciador é a instância implícita, o "autor" pressuposto pelo enunciado; o narrador é aquele a quem o enunciador delega a voz, ele assume, portanto, o papel de contar a história; o ator central do enunciado é aquele que, instalado no narrado, vive a história relatada pelo narrador. Essa questão das identidades foi aprofundada em Barros (2012).
} 
Já o efeito de identificação entre enunciador e ator do narrado é produzido por meio da identidade do nome na capa do memorial e do nome do ator do narrado, e é reforçada pela lista de publicações reconhecidas como de autoria do ator do narrado, tanto quanto do enunciador, entre outras estratégias. Ressaltamos ainda que o próprio título dos textos, que inclui a menção ao gênero memorial acadêmico, um gênero autobiográfico, corrobora tal efeito.

Esses efeitos de identificação entre enunciador, narrador e ator do narrado são relevantes para o exame do éthos do enunciador do gênero em questão, pois fazem com que o modo como o narrador se mostra no texto e ainda aquilo que é dito sobre o ator do narrado interfiram na imagem do enunciador, conforme veremos. Não se pode afirmar que a imagem que se cria para o ator do narrado corresponda, exatamente, ao éthos do enunciador; por exemplo, se o narrador declara todo o tempo que o ator do narrado é o melhor em tudo que faz ("eu sempre tirava as maiores notas, era o mais inteligente da sala"), é possível que se crie uma imagem mais de arrogância que de eficiência para o enunciador. No entanto, se o ator do narrado é apresentado como alguém que descobre ou cria sempre algo de novo, a reiteração de figuras e temas relacionados à novidade pode contribuir para conferir traços de um cientista inovador ao enunciador. Isso significa que as competências, os afetos e as ações atribuídas ao ator do narrado participam da construção do éthos por conta do efeito de identificação entre o ator do narrado e o enunciador, ainda que não, necessariamente, de forma direta.

Passaremos, a seguir, à análise de nosso corpus, por meio da qual, procuraremos tanto verificar como o éthos do enunciador é produzido, ou seja, por meio de que recursos textuais e discursivos, quanto verificar se esses recursos, bem como seus efeitos mantêm-se os mesmos em memoriais de diferentes áreas. Desse modo, optamos por examinar os memoriais das Biológicas e das Humanas separadamente, para ao final desenvolvermos algumas considerações mais gerais acerca da construção da imagem do enunciador do memorial acadêmico.

\section{Memoriais do Instituto de Biociências e da Faculdade de Medicina}

Iniciaremos a análise pelos memoriais escritos no Instituto de Biociências (IB) e na Faculdade de Medicina (FM) da USP. Alguns aspectos relevantes para a construção do éthos do enunciador serão examinados, como a oscilação de um modo de ser marcado pela cientificidade e, ao mesmo tempo, pela sensibilidade frente ao mundo; pela temática da inovação; pela construção do efeito de singularidade; e ainda pela temática da cooperação.

Já afirmamos que os memoriais procuram elaborar um percurso profissional, intelectual e acadêmico, o que se nota pela predominância de temas e figuras ligados à vida profissional e intelectual do candidato, como vemos a seguir: 
Desta forma, tenho a pretensão de continuar a desenvolver atividades de ensino, pesquisa e extensão no Depto. de Ecologia (IB, USP), de ampliar as abordagens e parcerias e fomentar a formação de recursos humanos. Viso elevar o nível educacional e de conscientização da população brasileira, mas sem me esquecer das publicações em revistas especializadas de alto nível de impacto (POMPÊO, 2007, p. 10, grifo nosso).

A reiteração de figuras e temas próprios ao universo da pesquisa, do ensino e da vida universitária ("atividades de ensino, pesquisa e extensão"; "Depto de Ecologia"; "IB-USP"; "nível educacional"; "formação"; "parcerias"; "publicações em revistas especializadas de alto nível de impacto") constroi o pertencimento do enunciadorcandidato à comunidade acadêmica, constituindo-se como um elemento essencial para a produção do papel temático de professor-pesquisador para esse enunciador.

Esse papel é reforçado pelo emprego dominante da norma culta em registro formal da língua portuguesa, pelo emprego de metalinguagem específica a cada área e subárea científica ("cavernas areníticas"), pelo uso abundante de topônimos ("município de Altinópolis", "UFSCar"), cronônimos ("em setembro de 1981”) e antropônimos ("Nelson da Silva César Junior") na reconstrução do passado lembrado, bem como pela menção a documentos que acompanham o texto, "comprovando" o desempenho do professor-pesquisador ao longo de sua carreira ("DOC1"; "DOC2", etc.). Tudo isso reforça a imagem de competência do enunciador, capaz de apresentar sua vida de forma objetiva, distanciada, detalhada, organizada e documentada. É como se o relato da vida fosse fruto de uma pesquisa bem fundamentada e que é apresentada para o enunciatário segundo o rigor, a didática e a clareza que se espera de um professor-pesquisador.

Tais recursos são responsáveis ainda pela produção do efeito de realidade, ou seja, da ilusão de que os eventos narrados de fato ocorreram. É o que vemos no fragmento que segue:

Eu, em conjunto com o químico Nelson da Silva César Junior, fomos os primeiros a explorar as cavernas areniticas no município de Altinópolis, trabalho apresentado no I Simpósio Paulista de Espeleologia, ocorrido na UFSCar, em setembro de 1981, evento organizado pelo GAE (POMPÊO, 2007, p. 4-5, grifo nosso).

Apesar de haver a utilização extensiva de estratégias que produzem efeito de objetividade e de cientificidade, encontramos também nos textos analisados o emprego recorrente de um léxico passional ou sensorial, da pontuação com impacto expressivo, entre outros recursos que contribuem para criar uma imagem de um professor-pesquisador sensibilizado pelo mundo. O enunciador mostra-se como alguém que possui uma relação também passional com seu trabalho. $\mathrm{O}$ ensino, a pesquisa e a vivência acadêmica são concebidos como fontes de prazer, capazes de alterar os estados de alma do ator do 
narrado, do narrador e, ainda, do enunciador. Como mostram os fragmentos a seguir, os memoriais em questão exploram de forma bastante contundente essa dimensão da afetividade, que é reforçada ainda pelo uso da debreagem enunciativa da enunciação e do enunciado (FIORIN, 1994) no que diz respeito à pessoa: o narrador se coloca como um eu que conta sua própria história.

Meu fascínio pelo Transplante aconteceu desde o primeiro contato. Racionalmente, este profundo interesse pelo Transplante pode ser justificado por ser uma subespecialidade que consegue integrar Nefrologia, Clínica Médica e Imunologia, além do desafio apaixonante e envolvente de transformar a cruel evolução natural de uma doença crônica, que ainda não tem opção de cura, numa evolução mais favorável através do transplante de um órgão normal (NORONHA, 2010, p. III, grifo nosso).

E foi assim que conheci a Professora Nanuza Luíza de Menezes!!! O Professor Paulo Pasquarelli levou-me até a sala da professora Nanuza, que nos recebeu com sua alegria e otimismo contagiantes. Lembro-me como se fosse hoje! E assim começou a minha relação com a pessoa maravilhosa, a grande pesquisadora, a pesquisadora que tem "a generosidade do saber" e a grande responsável pela minha vida acadêmica (ANGYALOSSY, 2006, p. 1, grifo nosso).

O prazer sentido pelo narrador no presente ou ao longo do percurso do ator do narrado no passado parece estar fortemente relacionado com a realização de um desejo, uma vez que a carreira é, muitas vezes, entendida como algo que coloca o sujeito em conjunção com objetos almejados desde a infância. A vocação, de que tratam tantos memoriais, diz respeito a esse desejo primordial que direciona o percurso do candidato. Marques, por exemplo, brinca com a ideia de ter nascido cientista, enquanto Latronico expressa sua vocação para a docência: "Remeto-os aos primórdios de minha infância na crença de que nasci cientista, ou pelo menos muito curioso" (MARQUES, 2007, p. 2); "Sinto-me totalmente vocacionada para exercer a função de docente [...]. Desempenho esse papel com entusiasmo, responsabilidade e grande prazer" (LATRONICO, 2010, p. 23, grifo nosso). Podemos, portanto, falar na presença de uma isotopia temática da vocação no gênero memorial, que é figurativizada de diferentes maneiras em cada texto, produzindo a imagem do professor e do pesquisador vocacionado.

Outra temática recorrente é a da inovação. Sob figuras variadas, como a da descoberta, da invenção, do pioneirismo, entre outras, a inovação é vista como uma ruptura eufórica no estado de coisas, como notamos nos seguintes comentários: “[...] trabalho este pioneiro no Brasil na época (ANGYALOSSY, 2006, p. 2; “Até o momento descrevemos nove espécies novas de monocotilídeos [...]” (MARQUES, 2007, p. 13); “[...] Em 2002 publiquei o primeiro trabalho no Brasil do tratamento do câncer cutâneo 
com imunomodulador" (FESTA NETO, 2009, p. 87); “[...] achados originais obtidos" (LATRONICO, 2010, p. 60)”; “[...] aplicação inédita” (NORONHA, 2010, p. VI). Logo, valorizam-se, nesses memoriais, as experiências aspectualizadas pela incoatividade.

Tanto a incoatividade reiterada quanto a passionalização textual ou ainda o emprego da debreagem de pessoa enunciativa da enunciação e do enunciado (FIORIN, 1994), dos quais já tratamos brevemente, contribuem para a produção do efeito de singularização do enunciador, afinal, ele possui uma relação inigualável com seu ofício, pois afetiva, vocacionada e ainda marcada pela inovação, pela produção de algo único, sem precedentes. Tal efeito de singularização é extremamente saliente nos memoriais estudados, havendo inclusive outros recursos que o reforçam. A incorporação da vida pessoal, por meio de temas e figuras da vida privada e familiar, por exemplo, contribui para tornar o ator do narrado e também o narrador e o enunciador sujeitos que possuem uma trajetória específica, singular, diferente das demais, como se nota quando Noronha se mostra uma médica que também gosta de bossa nova e de música clássica.

Mesmo com a educação rígida que recebi pude aproveitar grande parte de minha infância e adolescência brincando na rua, que na época era possível, principalmente andando de bicicleta ou empinando pipas, que eu mesma confeccionava. Por influência de minha irmã, meu ídolo, cresci ouvindo bossa nova e música clássica (NORONHA, 2010, p. I).

O tom - ou "a dimensão vocal do enunciador, desvelada pelo discurso" (FIORIN, 2004, p. 19) - empregado para contar o passado também não é sempre igual, sendo esta outra estratégia que age no sentido de tornar o enunciador singular. Há textos mais grandiloquentes, mais irônicos, mais saudosos, mais contidos, entre outros. Comparando os trechos seguintes podemos ter uma boa ideia dessa enorme diversidade, já que o primeiro assume um tom mais poético, enquanto o segundo é mais debochado: "Nasci na capital de São Paulo e acredito não ter tido uma infância diferente dos netos de imigrantes que aqui nasceram. Pipas, bolinhas de gude, futebol, pés na água após as chuvas" (FESTA NETO, 2009); "Foi excelente [volta à clínica médica], pois nunca mais voltei a ter dúvidas de que clinicar não era o que eu queria fazer" (CHAUIBERLINK, 2006, p. 8).

Especificamente no Instituto de Biociências, é recorrente o emprego de diversos tipos de humor, o que permite a construção de simulacros diversificados para o enunciador. O texto de Chaúí-Berlink, que acabamos de citar, é cheio de ironias e mesmo de autoironias que produzem a imagem de um enunciador de inteligência ágil, agudo. É diferente de outras formas de humor que apontam para um éthos mais leve, brando, amigável, como em: "Na época, Ubatuba era muito diferente do que é hoje, mas chovia o mesmo tanto" (MARQUES, 2007, p. 2).

Ainda com relação à diversificação de tons, nota-se que há textos mais formais, que revelam um professor-pesquisador mais sério, cerimonioso, enquanto outros incorporam, com maior frequência, gírias e vocabulário mais popular, criam efeitos de 
oralidade, misturando, desse modo, normas e registros. Tal forma de utilizar a linguagem permite a depreensão de um éthos mais descontraído, mais expansivo. Comparemos, por exemplo, duas formas de apresentar uma crítica, a primeira é mais contida, já a segunda mais inflamada:

Na discussão sobre a Pesquisa Clínica, cabe uma reflexão crítica importante sobre sua forma de atuação, visto a forte interferência que a Indústria Farmacêutica exerce sobre as atividades que deveriam ter um perfil predominantemente acadêmico (NORONHA, 2010, p. XXVII).

E chega de "sacanear" aluno! (CHAUI-BERLINK, 2006, p. 53).

Alguma diversidade pode ser notada ainda na edição dos textos. Há a exploração das possibilidades de variação de fontes, qualidades de papel, uso de imagens, cor de fonte e cor de papel, etc. Cada exemplar ganha, dessa maneira, uma fisionomia, até certo ponto, única, sendo a edição, portanto, outro elemento que corrobora o fortalecimento do efeito de singularidade do enunciador.

Apesar da diversidade, é possível observar certa tendência na edição dos textos de cada curso ou instituto. No Instituto de Biociências, a edição dos memoriais mantém-se muito próxima à das teses e dissertações: as capas são, no geral, pretas ou azuis, com escritos em preto, dourado ou prateado; o tamanho é o A4; a folha é a sulfite (papel ofício ou apergaminhado); a fonte no corpo do texto é Arial 11 ou Times New Roman 12; etc. Já na Medicina há certo distanciamento com relação a esse padrão que se estabeleceu no meio acadêmico. Nos memoriais estudados da FM, percebe-se uma exploração muito exacerbada dos recursos visuais e gráficos. Há grande diversificação na escolha do tipo e da cor das fontes (não encontramos apenas Arial e Times New Roman), da cor e do tipo de papel (textura e gramatura), além de haver enorme emprego de fotografias, gráficos e tabelas, como se nota na Figura 1.

Figura 1 - Memorial da Faculdade de Medicina
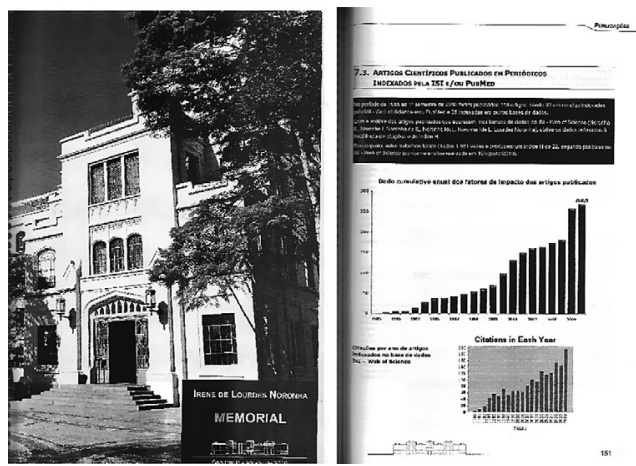

Fonte: Noronha (2010, capa, p. 181). 
Podemos afirmar que os memoriais da Medicina se aproximam muito de um livro, pois utilizam quase sempre a brochura como processo de encadernação, trazem imagens na capa, optam pela capa dura, entre outros elementos. Enfim, distinguem-se bastante do que seria a edição de uma tese ou de uma dissertação, a não ser pela manutenção do tamanho e do formato das edições (A4). Logo, com relação à fabricação desse objeto "memorial", podemos afirmar que eles se afastam das práticas acadêmicas de edição e se aproximam das práticas das editoras. Nesse sentido, apesar da diversificação, assumem, ainda que não de forma integral, um novo padrão: o do livro que circula no mercado editorial. Isso contribui para criar uma imagem de eficiência para o enunciador e de certo tipo de profissionalismo, mais afim com as modernidades tecnológicas e com o mercado. Temos aqui um sujeito arrojado. Ao mesmo tempo, não se deixa de lado a singularização do enunciador, já que os memoriais-livros possuem, cada um, suas especificidades.

Ao tornar-se eficiente, singular e arrojado, esse enunciador pode talvez destacar-se, mostrar-se competitivo, termo empregado diversas vezes nos textos para apresentar as qualidades de um laboratório, de um pesquisador, etc. Em Latronico, por exemplo, a palavra aparece três vezes ao longo de apenas duas páginas: "Ao longo dos últimos 15 anos, contribuí com a implantação de um laboratório de pesquisa competitivo [...] (LATRONICO, 2010, p. 1, grifo nosso)"; "O programa de internato bem estruturado e o convívio com colegas muito interessados e competitivos [...] estimularam o meu preparo para as provas de residência médica" (LATRONICO, 2010, p. 2, grifo nosso); "Em fevereiro de 1989, fui selecionada após processo competitivo a ocupar uma das quatro vagas de residência na Disciplina de Endocrinologia e Metabologia, sob a chefia do professor doutor Bernardo Léo Wajchenberg" (LATRONICO, 2010, p. 2, grifo nosso).

Conforme vemos nos excertos, a competitividade recebe sanção positiva nos memoriais da Medicina, o que vai ao encontro da exposição de forma bastante detalhada e, principalmente, quantificada da produção do candidato. Quase todos os exemplares que examinamos da FM apresentam, além dos tradicionais indicadores de produção, gráficos de diferentes tipos (pizza, barras e outros) para mostrar quanto o candidato publicou, quanto é citado, quantos alunos formou, quanto seus alunos publicaram, quantos cursos ofereceu, entre outros dados.

A quantificação é também largamente explorada com a finalidade de valorizar pesquisadores e professores com os quais o memorialista teve contato ao longo da vida: "Nessa ocasião, fui aceita para o estágio no laboratório do professor doutor. George P. Chrousos, um dos maiores investigadores da endocrinologia pediátrica com aproximadamente 800 publicações e várias premiações internacionais" (LATRONICO, 2010, p. 2). Ao mostrar a relevância acadêmica de seus mestres e dos demais profissionais com os quais trabalha ou trabalhou, o professor-pesquisador também comprova a sua própria competência, uma vez que nem todos são aceitos para fazer certas parcerias ou para atuar em certos laboratórios. Dessa forma, é afirmada a inserção do candidato na pesquisa nacional e, às vezes, internacional, sem que se deixe de recorrer ao recurso da modéstia. A fundamentação da competência ocorre também por meio da inserção de 
cartas de agradecimento de alunos e pacientes, algo que podemos encontrar no corpo do texto ou nos anexos de alguns memoriais da FM.

É interessante notar, no entanto, que a construção mais explícita de uma imagem positiva do ator do narrado, que se reflete no narrador e no enunciador, parece não ser avaliada da mesma forma nas duas instituições de que estamos tratando nesta parte do artigo. Nos memoriais da FM, encontramos passagens em que o narrador elogia de forma menos velada o ator do narrado, embora, mesmo nesses casos, o elogio seja "mediado", no sentido de que se baseia no que outros dizem. É o que ocorre quando Latronico (2010, p. 8) afirma que suas publicações em revistas médicas com alto impacto científico: "marcam de forma definitiva o meu nome no cenário de pesquisa internacional". Vejamos outro exemplo: "Com isso alcancei respeito nesta área, sendo considerada muito boa professora pelos alunos e 'good speaker' para palestras e conferências profissionais” (NORONHA, 2010, p. XVII).

Comparando os textos do IB e da FM, podemos dizer que os da FM revelam uma competitividade intensificada. Sobretudo nos memoriais escritos para concursos de titularidade da FM, encontramos uma parte destinada aos planos para o futuro, que aparecem, quase sempre, sob a forma de promessas. Isso mostra que a manipulação sobre o enunciatário é feita de forma mais explícita, sem dissimulações como em outros memoriais. É próprio do gênero construir a imagem positiva do enunciador, a peculiaridade que existe em muitos dos textos dos professores que almejam a titularidade na Medicina, como vemos em Latronico (2010), é o oferecimento mais escancarado de objetos-valores (o desenvolvimento de metodologias inovadoras, por exemplo) como uma sanção pragmática a ser dada à banca e à comunidade científica no caso da aprovação do candidato. Isso talvez seja revelador do papel diferente que esse concurso possui nas duas instituições investigadas.

Como Professora Titular, desejo manter minha contribuição no crescimento da Disciplina de Endocrinologia e Metabologia da Faculdade de Medicina da Universidade de São Paulo. No âmbito da pesquisa, planejo fomentar o desenvolvimento de metodologias científicas inovadoras nas áreas de genética clínica e molecular voltadas para a investigação dos distúrbios endócrinos. Participarei ativamente na construção de novas parcerias científicas nacionais e internacionais com o propósito de incrementar a produção científica local e aprimorar a capacitação de profissionais médicos e não-médicos, fortalecendo ainda mais a imagem sólida de liderança de nossa Instituição. Comprometo-me em desempenhar com entusiasmo e interesse minhas atividades de docência e extensão, e colaborar na obtenção de um atendimento médico de qualidade e de um ensino médico de excelência. Finalmente, prometo exercer esse cargo com responsabilidade e compromisso social seguindo as mesmas promessas proferidas no início da minha carreira como médica (LATRONICO, 2010, p. 1, grifo nosso). 
Outro aspecto que merece destaque nos memoriais das duas instituições em questão é o fato de tratarem com frequência das parcerias e colaborações estabelecidas pelo ator do narrado ao longo de sua carreira. A presença dos laboratórios é bastante central tanto nos textos do IB quanto da FM, além disso, é dado, nos exemplares examinados, grande espaço para as colaborações nacionais e internacionais, que, em alguns memoriais, chegam até mesmo a constituir um capítulo específico: "Formação de Grupos Cooperativos" (FESTA NETO, 2009). Em diversos momentos inclusive, o ator do narrado torna-se a figurativização de um actante coletivo: o laboratório ou o grupo de pesquisa.

O emprego do nós nos trechos apresentados a seguir confirma uma visão de ciência e de vida acadêmica inclinada, em certos aspectos, ao fazer coletivo: "Este foi um período enriquecedor, pois analisávamos e discutíamos as semelhanças e diferenças estruturais das madeiras" (ANGYALOSSY, 2006, p. 2, grifo nosso); “Em 1990, em associação com o Professor José Antonio Sanches Jr. Idealizamos e criamos o Ambulatório de Oncologia Cutânea" (FESTA NETO, 2009, grifo nosso). É importante frisar que sob esse pronome estão também muitas vezes os alunos, vistos como parceiros no processo de construção do conhecimento. No IB, há memoriais em que o eu e o nós são usados com frequência próxima, sempre com um pequeno ganho para o primeiro. Isso já não ocorre nos exemplares da FM em que o nós aparece bastante, mas em momentos bem delimitados. De qualquer forma, fica registrada a inclinação para a valorização do trabalho cooperativo nos textos das Biológicas, o que tem consequências para a produção do éthos do enunciador.

Logo, parece que o enunciador dos memoriais do Instituto de Biociências e da Faculdade de Medicina da USP projeta uma imagem de um professor-pesquisador que domina o fazer científico, que tempera a objetividade e o distanciamento com algum afeto, que é singular, arrojado, competitivo e cooperativo. Ainda que essas características não sejam igualmente distribuídas entre os dois cursos, nem entre os diferentes memoriais, podemos identificá-las, por sua reiteração, como tendências dessa grande área.

\section{Memoriais do Curso de Letras e da Faculdade de Educação}

Passaremos agora a tratar dos memoriais produzidos no Curso de Letras (CL) da Faculdade de Filosofia, Letras e Ciências Sociais (FFLCH) e na Faculdade de Educação (FE), ambos da USP, conforme já foi mencionado. Para isso, abordaremos alguns aspectos que parecem relevantes na construção desse conjunto de textos, como a produção da cientificidade, da dimensão passional e do efeito de singularidade, bem como a oscilação entre uma linguagem mais poética e uma mais analítica, e a elaboração da temática da inadequação.

Também nos memoriais examinados da área de Humanas, observa-se a recorrência de figuras e temas ligados à vida acadêmica ("tese de livre-docência"; "pesquisa"; 
"hipóteses"; "palestras"; "textos"; "citações”) e ainda a dominância da norma culta em registro formal e o emprego de metalinguagem própria a cada área e a cada subárea ("sistemas de flexão de uma língua"; "sistema anafórico"), construindo a imagem do enunciador, como de um professor-pesquisador, conforme notamos nos fragmentos a seguir:

A tese de livre-docência "O português brasileiro: uma língua voltada para o discurso" pode-se dizer que representa a conclusão de uma sequência de pesquisas sobre a hipótese de que as características dos sistemas de flexão de uma língua são responsáveis por sua estrutura sentencial e pela distribuição e interpretação das formas integrantes de seu sistema anafórico (NEGRÃO, 2004, p. 50, grifo nosso).

Em meados de 1993, o SENAC me convidou para fazer uma palestra em Salvador, no lançamento do livro África: moda, cultura e tradição, que reunia textos de Fábio Ávila e Fábio Leite (e algumas citações de minha tese) (219), sobre fotos do vestuário africano feitas por Maureen Bisilliat em Abijan (PETTER, 2008, p. 24, grifo nosso).

Esses excertos também trazem topônimos ("Abijan"), antropônimos ("Maureen Bisilliat") e cronônimos ("meados de 1993"), bem como a indicação da documentação que acompanha o texto ("219"), o que confere ao relato efeito de objetividade e de realidade e, ao enunciador, a imagem de competência, pois revela-se um pesquisador capaz de apresentar os dados de forma objetiva, distanciada, clara, organizada, e que atende, portanto, às expectativas atribuídas à comunidade acadêmica.

Como nos textos das Biológicas, os recursos que produzem efeitos de objetividade e cientificidade são mesclados àqueles que apelam ao sensorial e ao passional. As escolhas discursivas semânticas resultam na iconização ${ }^{4}$ do passado lembrado e ainda na construção de um vínculo afetivo do narrador com esse passado.

Muitos acham que nasceram predestinados a grandes feitos. Eu nasci, sem qualquer predestinação para as alturas, em Birigui, uma cidadezinha qualquer. Na infância, fui um menino comum. Tive uma meninice típica de interiorano: brincava, passeava, frequentava o grupo escolar. A família era enorme: primos, tios... Sobre todos pairava a figura do nono. Fiz ginásio e clássico. Fui muito bom aluno. Talvez porque em casa me tenham incutido um profundo senso do dever (FIORIN, 1994, p. 8, grifo nosso).

No trecho citado do memorial de Fiorin, por exemplo, o narrador se refere ao avô como "nono", algo revelador de suas origens e da afetividade que subjaz às relações

${ }^{4}$ Entendemos iconização como a última etapa da figurativização, em que as figuras são dotadas de investimentos particularizantes (GREIMAS; COURTÉS, 2008, p. 251). 
entre neto e avô. Além disso, o narrador emprega a primeira pessoa do singular para se referir a si e ao menino que foi no passado, o que também contribui para o fortalecimento da afetividade. Essa dimensão mais sensível emerge não apenas quando o foco é a infância, mas também atrelada ao trabalho acadêmico e intelectual, confirmando as semelhanças entre os memoriais examinados das áreas de Humanas e de Biológicas, conforme comprovam as citações que seguem:

De qualquer forma, vejo aí um fio, uma linha que parece tecer esta trajetória, que costura e aproxima fatos e lhes dá algum sentido. Participar de centros de ciência, estudar ciências, estudar o ensino de ciências, pesquisar os museus de ciências. Foi aí que me encontrei! (MARANDINO, 2012, p. 4, grifo nosso).

Mas rapidamente desenvolvi uma paixão - insensata, como todas as verdadeiras paixões - pelo ensino (CARVALHO, 2013, grifo nosso) $)^{5}$.

Nos fragmentos mencionados, parece que a dimensão passional e sensorial transborda para o presente da narração; não é apenas o eu do passado que exclama ao perceber ter encontrado o seu caminho, ou ainda que se sente um apaixonado pelo ensino, mas também aquele que narra. Assim, por recursos diferentes - escolha lexical, pontuação, etc. - a relação de prazer com uma boa parte do que constitui o trabalho acadêmico vai sendo estabelecida de forma persistente.

Como vimos nos memoriais das Biociências e da Medicina, a satisfação revivida pelo narrador no presente relaciona-se, entre outros aspectos, à realização de um desejo. A carreira acadêmica é apresentada como a possibilidade de conjunção com o objeto buscado, em certos casos, desde a infância, e como o elemento que atribui certa direção ao percurso do sujeito, ainda que haja espaço para interrupções e mudanças de rumo nos memoriais. Portanto, o tema da vocação, que produz a imagem do enunciador vocacionado para a pesquisa e/ou para a docência, também se faz presente nas Humanidades, como notamos a seguir:

Poderia iniciar minha narrativa dizendo que a opção pela educação não foi uma tomada de posição madura e adulta. Pelo relato de meus pais, e pela lembrança que tenho de alguns fatos da infância, sei que desse período foi a preferência por não deixar sem as letras as pessoas mais simples que passaram por mim. [...] (QUADROS, 2006, p. 10).

No caso dos memoriais das Humanas, algo que chama a atenção com relação à exploração do sensível é a utilização de uma linguagem mais literária, como notamos a seguir: "Importa o tato do estojo de madeira ou de lata, em que se guardavam lápis,

\footnotetext{
Não foi possível obter as páginas do documento, pois ele se encontra somente em formato físico na biblioteca da Universidade de São Paulo, não sendo possível seu acesso no momento devido à pandemia do coronavírus.
} 
caneta e sonhos; o cheiro da borracha de apagar; o avental branco com inscrição em linha azul, Q.A., Quinzinho do Amaral, uniforme a ser conservado limpo" (DISCINI, 2002, p. 8). Por meio de uma espécie de hiperfocalização, Discini recupera a experiência da escola a partir sobretudo das qualidades sensoriais dos objetos (o branco do avental, a sensação tátil do estojo) e de um efeito de suspensão da passagem do tempo, dado pela rarefação dos verbos e pelo emprego do presente em "importa".

Poderíamos supor que essas passagens mais próximas do texto literário fossem aparecer apenas nos memoriais do Curso de Letras, mas o que pudemos observar é que, nos exemplares da Faculdade de Educação, também se mostram frequentes:

Nasci de frente para o Atlântico (este mar/morte terrificante e fascinante, ao mesmo tempo), num hospital do porto de Santos ("De Todos os Santos"). O cais é sempre este ponto seguro da terra que nos arremessa à incerteza do mar, à sua concretude líquida. Numa quarta-feira (no meio da semana), à meia-noite (no meio do dia e da noite). No transitar de um dia para o outro, sob o domínio lunar da escuridão luminosamente estrelada por gotas de chuva-constelações, num final de 23 de outubro de 1963. Noite chuvosa em que meu pai escorregava numa poça de água a caminho do hospital, destas mesmas que planteiam a calçada e o asfalto com múltiplos lagos que escondem sua profundidade na superfície (SANTOS, 2003, p. 7).

Nesse fragmento, altamente icônico, chama a atenção o grande apelo aos aspectos sensoriais da cena (a luminosidade, a escuridão, a liquidez, a concretude, etc.) e ainda a justaposição de termos com significados opostos, como em terrificante/fascinante; ponto seguro da terra/incertezas do mar; no meio do dia/ no meio da noite; escuridão/ luminosamente estrelada; profundidade/superfície; gotas de chuva/constelação (aqui a relação opositiva é menos evidente talvez, mas trata-se de aproximar concentração e expansão). Em termos tensivos (ZILBERBERG, 2006), o que ocorre é um salto semântico, em que se passa de uma polaridade a outra por meio de uma hiperaceleração, ou seja, não é percorrido um caminho gradativo, como em: escuridão-penumbra-luz fraca-luminosidade. O impacto dessa supressão de intervalos, que aproxima extremos, é grande sobre o enunciador e também sobre o enunciatário, capturados pelo texto por meio da afetividade. Também poderíamos mencionar como responsáveis pela apreensão sensível do sujeito da enunciação as aliterações e assonâncias, como em mar/morte; terrificante/fascinante, etc. Todos esses elementos contribuem para a construção para o enunciador de um papel temático que flerta com o do escritor.

Contrapõem-se aos momentos de intensificação do sensível, passagens, de certo modo, mais analíticas:

Cursei grande parte de minha escolaridade básica no Colégio Fish e na década de 70 e início de 80, no Colégio Anderson, na Tijuca, no Rio 
de Janeiro. Lá as aulas de ciências eram muito especiais. Tínhamos laboratórios grandes e bem equipados, e as aulas práticas eram comuns, especialmente no "ginásio".

Influenciado, muito provavelmente, pelo movimento experimental e empirista do ensino de ciências e pelo fato de já ter sido uma escola profissionalizante $[\ldots]$.

Não é fácil localizar o início das feiras de ciências no Brasil [...]. Como nos conta Myriam Krasilchik, em seu célebre livro "O professor e o ensino de ciências", de 1987 [...].

Esta ênfase experimental se mantém até hoje, para além das diferentes influências teóricas dos momentos históricos posteriores. Remodelou-se a partir das novas realidades históricas e políticas dos anos subsequentes da década de 1990 e continua sendo ressignificado nas discussões sobre a melhoria do ensino de ciências deste século XXI (MARANDINO, 2012, p. 3).

Deu-me um caderno, escreveu na primeira linha 'a-e-i-o-u' e mandou que eu copiasse aquelas letras na página inteira. Depois deu um visto e passou uma nova lição, desta vez numa pequena lousa. No ano seguinte, ao entrar na primeira série, já estava praticamente alfabetizado (a despeito do tradicionalismo caricatural de suas aulas e de seu total desconhecimento da psicogênese da língua escrita!). O que dela diriam os zelosos vigilantes das renovações didático-metodológicas? Como se forma um alfabetizador? (CARVALHO, 2013).

Em Marandino (2012), vemos a construção do éthos da pesquisadora como especialista no ensino de ciências, não porque o narrador (identificado ao enunciador) afirma explicitamente ser essa a sua especialidade em diversos momentos do texto, mas essencialmente por fazer uma espécie de pequena história do ensino de ciências a partir de sua própria experiência escolar. Além disso, utiliza diversos recursos próprios ao métier, como o exame de um caso individual à luz dos fatos históricos e sociais (relaciona a ênfase nas aulas em laboratório ao "movimento experimental e empirista do ensino de ciências"), a utilização de metalinguagem específica, a fundamentação por meio de referências bibliográficas, a análise dos impactos do passado nos tempos atuais. Todos esses elementos contribuem para a construção do papel temático do enunciador como de um cientista e pesquisador competente.

Já o narrador de Carvalho (2013), à medida em que relata o seu passado, procura discutir a questão de como se forma um professor, questão esta que aparece desde o começo de seu texto e que dá origem a outras perguntas mais específicas, tais como "Como se forma um alfabetizador?", que se refere à passagem sobre o papel da irmã em sua alfabetização. Assim, o memorial apresenta-se como oportunidade de refletir sobre 
uma problemática cara aos educadores, fortalecendo o papel temático do enunciador como de um pesquisador da educação.

É interessante notar que essa postura mais científica frente ao próprio passado é, em algumas raras passagens, combinada a um texto bastante poético, o que complexifica um pouco a questão. Para mostrar as diferenças entre o método em que foi alfabetizado e um outro método, muito provavelmente influenciado pela figura de Paulo Freire, Aquino (2009) utiliza-se das palavras frequentemente selecionadas por cada um. Por meio dessa metonímia, confere certa corporeidade a ideias bastante abstratas:

Como toda criança do início da década de 1970, fui alfabetizado pelo indefectível método Caminho Suave. Naquele tempo a abelha não havia ainda se transmutado em amor; laranja em liberdade; a unha no universo. Habitava-se um mundo de superfícies planas, imediatas: elefante, faca, macaco, navio, ovo, pato, queijo e rato (AQUINO, 2009, p. 4).

A observação e a análise da própria vida a partir de um referencial teórico parecem ser bem menos frequentes nos memoriais do CL que nos da FE. Nos textos das Letras, as reflexões sobre a vida passada versam, em grande parte, sobre o sentido dessa vida. Escolhas e caminhos tomados são debatidos, tendo como foco, entre outros aspectos, sua coerência com o todo. O memorial é apresentado pelo narrador, de forma explícita, como oportunidade de reconstrução da identidade. Isso também aparece nos textos da Educação, mas nestes tal questão possui espaço de debate mais restrito. Outro ponto que merece ser comentado é que a busca pelo sentido da vida confunde-se, especialmente nos exemplares do Curso de Letras, com a busca pelo sentido da narrativa elaborada no memorial. Pensar sobre a vida não parece, portanto, ser algo visto, em boa parte dos memoriais do CL, como distinto de pensar sobre sua organização em forma de relato. Estabelece-se, desse modo, um nível metalinguístico de comentário sobre a escritura memorialística, conforme vemos em Negrão (2004, p.5): “Ao empenhar-me nesta tarefa de construção de meu memorial, fui-me dando conta do estranho jogo entre as certezas que geraram certas escolhas e a casualidade que me levou a caminhos inimagináveis em minha carreira acadêmica".

Nesse nível metalinguístico, em que o narrador se encontra bastante destacado de sua narração, são ainda tecidos muitos comentários sobre o gênero memorial, algo que aparece com frequência mais baixa nos textos da FE. Fiorin (1994), por exemplo, desenvolve uma espécie de introdução no seu memorial em que discute as características do gênero: "Memorial é um texto em que são consignados fatos de que se quer lembrar. Esse termo é derivado de memória, a faculdade de conservar e de lembrar estados de consciência passados" (FIORIN, 1994, p. 4). Também chama a atenção nos textos das Letras a presença de reflexões sobre o próprio ato de narrar, interrompido para tornar-se o objeto com o qual o narrador interage: "Como contar, ainda que sumariamente, tudo o que pude ver, ouvir e pensar, em matéria de arte, ao longo do tempo em que estive fora? Confesso-me perplexo, sem saber por onde 
começar. No entanto, como é preciso, vou sugerir alguma coisa" (ARRIGUCCI Jr., 1990, p. 20).

O enunciador, identificado ao narrador, assume, portanto, o papel temático do pesquisador dos fatos linguísticos e literários. Está aí talvez uma das principais diferenças entre os memoriais produzidos na Faculdade de Educação e aqueles do Curso de Letras: naqueles, o acento incide sobre a análise da vida como parte de uma história da educação; nestes, sobre o exame da vida como linguagem, narrativa. Isso confirma que há competências esperadas do professor-pesquisador que são específicas a cada subárea.

Conforme já observamos ao analisarmos os textos do IB e da FM, há certa flexibilidade estilística no gênero memorial acadêmico, especialmente se levarmos em conta a esfera à qual pertence, a esfera acadêmica. Cada memorial, além de utilizar a debreagem enunciativa para discursivizar a pessoa (FIORIN, 1996) - o que já provoca o efeito de individuação -, parece procurar uma voz própria em meio aos outros, como é possível notar ao compararmos dois excertos pertencentes à parte introdutória de memoriais da Faculdade de Educação:

Assumo, aqui, a preocupação tomada por Hobsbawm em Tempos interessantes. Circunscrevo o relato à trajetória profissional. A vida pessoal ficará ao largo, denunciando o desconforto com o gênero autobiográfico. Recorto a escrita ainda um pouco mais. Restrinjo-me a tratar dos últimos 16 anos, momento em que iniciei no magistério de nível superior. A escolha se dá por pretender discorrer apenas sobre o trânsito intelectual na arena da história da educação. Os limites autoimpostos inibem a apresentação dos fatos vividos antes de 1987 (às vezes, entretanto, se insinuam sob forma de notas de rodapé), e respaldam uma abordagem que pende para a reflexão histórica e conceitual sobre temas de pesquisa. A investigação acadêmica e os grupos a ela associados constituem-se, assim, no centro da narrativa, o que não impede que as relações tramadas com a docência e a extensão sejam articuladas no texto (VIDAL, 2004, p. 4).

As imagens pululam hoje em minha memória assim como os insetos que se movimentam no final de tarde na despedida do sol e recepção do manto sereno da noite: crepusculário (SANTOS, 2003, p. 7).

A diversidade de tons empregados - mais analítico e distante no primeiro caso, mais poético e próximo no segundo - encontra eco em outros aspectos. Não comentaremos todos os pontos que seriam relevantes, mas gostaríamos de chamar a atenção para o fato de o texto de Vidal não tratar da infância ou de períodos anteriores à docência em nível superior, e ainda procurar velar ao máximo as interferências pessoais nas escolhas profissionais. Já o de Santos dedica uma longa parte aos seus tempos de menino, conta 
sobre o período em que atuou como bombeiro, fala dos filhos, dos casamentos, etc. Logo, as diferenças de tom são corroboradas pela variabilidade das isotopias temáticas e figurativas, entre outros recursos.

Quanto à questão da edição, percebe-se que, nos memoriais das Humanas, predominam as capas pretas ou azuis, com letras douradas ou prateadas, sem ilustração, bem como o emprego no corpo do texto da fonte Times New Roman ou no máximo da Arial. Além disso, é rara, para não dizer inexistente, a inserção de imagens no corpo principal do texto (elas às vezes aparecem em anexos ou nas capas, embora isso não seja habitual). A edição aproxima-se, portanto, mais do padrão de edição das teses e dissertações, fugindo disso a partir de elementos localizados. É o que vemos no memorial do professor Marcos Ferreira dos Santos, da Faculdade de Educação, que apresenta um texto não justificado e o uso da letra capital no início de cada seção: dois pequenos “desvios” daquilo que é mais comum em textos acadêmicos.

Figura 2 - Memorial da Faculdade de Educação

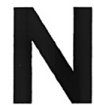

o esteio das reflexões e atitudes filosóficas e antropológicas, me fiz viajante de paragens distantes, pois elas aclaram o sentido de minha querência, de meu pago primeiro. Minha aldeia é o mundo e o mundo é minha aldeia. Atahualpa Yupanqui (o folklorista argentino que hoje se encontra no "céu dos bons cavalos" com todos os seus alazões de crinas de fogo, ao lado do louco e adorável astro meteórico Astor Piazzolla) dizia que "somente se é universal quando se canta a própria aldeia”. Destas paragens de matizes coloridos e também cinzentos, pude ver a confluência de caminhos diversos que me levaram a um ponto eqüidistante entre os Alpes e os Andes $^{2}$, no meio do Atlântico... talvez na aquosa Atlântida. No Alfa de tudo, no "A" da posição yogi de lótus indiana. Alpes que serviram de encosta para os meus tão queridos pensadores franceses: Mounier, Merleau-Ponty, Freinet, Gilbert Durand, Bachelard, o exilado russo Berdyaev e um

Fonte: Santos (2003, p. 6).

O que pudemos verificar, no que diz respeito às questões de edição, é que, nos memoriais das Humanidades, ocorre uma pequena fuga do padrão acadêmico - das teses e dissertações -, sem que seja estabelecido um novo padrão (o dos livros produzidos para circulação no mercado editorial, por exemplo). O efeito que se cria é de um éthos levemente desviante, criativo, que procura diferenciar-se de um modelo, ainda que de forma sutil. Os exemplares das Humanas não parecem feitos por uma editora, apresentando um "ar" mais artesanal.

Essa produção de um estilo levemente desviante, percebida no processo de edição dos textos, vai ao encontro de certos temas e figuras, conforme veremos. Especialmente nos memoriais da FE, o narrador ou o ator do narrado é, em algumas passagens, apresentado como alguém que não se adequa completamente aos modos de ser e de fazer esperados no meio acadêmico. A reiteração de tal estratégia discursiva, encontrada em muitos memoriais, sugere que essa postura, de certa forma confrontante ao que 
esses mesmos textos constroem como o mainstream acadêmico, é algo esperado e sancionado positivamente em discursos que circulam por algumas subáreas. É como se fosse adequado ser levemente inadequado em certos discursos, o que corrobora as observações já realizadas a respeito da edição. Os fragmentos abaixo ilustram nossas afirmações: Carvalho confessa sua falta de familiaridade com o éthos acadêmico; Arantes conta ter, em alguns momentos, abandonado certos pressupostos teóricos; Aquino assume seu gosto pela transgressão e seu sentimento de desconforto frente à vida em geral.

Ao contrário de muitos colegas, sobretudo os mais jovens, não vinculava a carreira acadêmica a pesquisas e publicações, mas ao ensino. Não se tratava de uma opção consciente de rejeição do produtivismo, cuja presença já se insinuava entre nós. A atitude se devia mais à falta de familiaridade com o ethos acadêmico do que a qualquer forte convicção contestatória (CARVALHO, 2013).

Devo confessar que, em muitos momentos, "abandonei" os pressupostos teóricos que deveria (e tentava) aplicar com meu pequeno "cliente" e deixei-me fascinar pelo insólito, tentando ler e ouvir o que ele, com poucas palavras e muitos sentimentos, me dizia. Espontaneísmo? Talvez. Cercada de quatro paredes me permiti "trocar de óculos" e pude ver coisas fantásticas! (ARANTES, 2012, p. 4)

Vem desse tempo, suponho, uma das marcas que me acompanhou pelo restante de minha trajetória escolar: o gosto pela transgressão (AQUINO, 2009, p. 5).

Em brevíssimo, porém, as coisas começariam a desencaixar. O sonho dourado de viver na capital esfumaçava-se. A vizinhança do apartamento alugado era tenebrosa. Os ônibus, muito cheios. Os colegas de USP, muito competitivos. Meu projeto de pesquisa, muito inconsistente. A vida, muito cara. As aulas de inglês que havia arrumado, mal pagas. Eu estava enfim batizado pela metrópole. Já era, definitivamente, um dos seus (AQUINO, 2009, p. 10).

Assim, podemos afirmar que, entre as estratégias que produzem o efeito de singularidade do enunciador dos memoriais do CL e da FE, estão a construção de uma vida singular (algo que a forte presença de figuras e temas ligados à infância vem reforçar); de uma escrita que flerta com a literária; de certa dimensão passional do texto; de modos de atuar próprios a cada área e subárea; de tons variados; e ainda de uma leve inadequação frente às forças institucionais. 


\section{Algumas considerações finais}

O exame dos memoriais de duas grandes áreas da USP, Biológicas e Humanas, confirmou a relativa variabilidade do gênero. Com relação à semântica discursiva, percebemos que todos os memoriais apresentam, de forma reiterada, temas e figuras ligados às memórias profissionais, escolares e intelectuais, o que constrói a imagem de um enunciador que é um pesquisador e um docente, um sujeito do meio acadêmico. Apesar disso, sobretudo aqueles das Humanas - mas não apenas eles - dão grande espaço para a vida familiar e privada, ainda que haja exemplares do Curso de Letras e da Faculdade de Educação que a deixem de fora ou muito nas entrelinhas.

Outro ponto para o qual gostaríamos de chamar a atenção é o fato de que, em todos os textos examinados, observa-se a necessidade de criação de uma imagem de eficiência e confiabilidade do enunciador, que passa pelo emprego dominante da norma culta em registro formal, pelo uso de metalinguagem específica a cada área e subárea, pela referência à documentação que acompanha o texto e ainda pelo uso abundante de recursos como os da ancoragem, realizada por meio da menção de nomes de pessoas e de lugares e ainda de datas oriundas de um discurso social partilhado e aceito como verdadeiro. No entanto, em todos os memoriais há algum espaço para informalidades, uso de expressões populares e de uma linguagem mais familiar.

Nos textos de Biológicas como um todo, encontramos a exacerbação da emoção em muitas passagens e, especificamente nos memoriais do IB, a incorporação de diferentes tipos de humor. Parece que essa é a maneira encontrada para a projeção da imagem de um enunciador que não quer se mostrar sempre neutro e distante, mas capaz de sensibilizar-se com o mundo e com as experiências que a profissão lhe proporciona. Já nos textos das Humanas, observa-se uma aproximação mais intensa da linguagem literária. Há passagens extremamente poéticas, em que o sujeito da enunciação é convocado a reviver o passado com o narrador e o ator do narrado, algo mais raro nos exemplares examinados das Biológicas.

Os trechos em que a dimensão passional e afetiva é menos convocada, que mesmo nos memoriais de Humanas são a grande maioria, também apresentam posturas distintas com relação ao emprego da linguagem. Além daqueles recursos já mencionados, como a ancoragem, nas Biológicas e, nesse caso, mais na Medicina que nas Biociências, notamos o emprego mais recorrente de dados quantificados e a inserção de documentos que comprovam as competências do enunciador (cartas de agradecimento de alunos, cartas de colegas elogiando o candidato, etc.). Já os memoriais do Curso de Letras e da Faculdade de Educação recorrem a outros procedimentos linguísticos e discursivos. Aqueles, com bastante frequência, desdobram o nível da narração num nível metalinguístico, em que se examinam o ato de narrar, o gênero memorial e o sentido da vida enquanto narrativa; estes, geralmente, analisam essa vida buscando inseri-la em um contexto mais amplo, especialmente o da história da educação, com base em uma bibliografia teórica aludida ou citada no corpo do texto. Dentro dessas linhas gerais das grandes 
áreas e das subáreas, cada memorial parece procurar uma maneira específica de contar a vida com um tom próprio.

É pertinente que comentemos também a variabilidade do gênero no que diz respeito à sua edição. É gritante a diferença no modo de conceber a edição nas Biológicas e nas Humanidades. Mostramos que, sobretudo na Faculdade de Medicina, os memoriais acabam por se parecer com um livro, enquanto aqueles do Curso de Letras ou da Faculdade de Educação se aproximam, no geral, da edição padrão de teses e dissertações, apresentando, no entanto, quase sempre um pequeno desvio com relação a esse padrão. Essa opção pelo memorial-livro na FM contribui para criar o efeito de inovação acadêmica, de eficiência e de modernidade no que diz respeito ao domínio de uma tecnologia, bem como de inserção no mundo do trabalho para além da esfera acadêmica.

Tais elementos parecem ir ao encontro do que ocorre na semântica discursiva do componente verbal dos memoriais. A isotopia temática da inovação e ainda a necessidade que o professor-pesquisador parece ter de mostrar suas qualidades de forma mais explícita contribuem para a construção de um éthos marcado pela inovação, singularidade, eficiência e competitividade na FM. Enquanto no CL e na FE, a estratégia de inserção da história singular num contexto mais amplo, a recorrência maior do recurso à modéstia, as isotopias que reiteram a figura do crítico, o emprego de uma linguagem mais literária em certas passagens parecem apontar para a produção de um éthos crítico, criativo e levemente desviante.

O caso dos memoriais do Instituto de Biociências é bastante peculiar, pois há textos que se aproximam mais daqueles das Humanidades, com relação à construção do éthos, e outros da Medicina. Há inclusive muitos que parecem combinar qualidades, projetando, por exemplo, um éthos crítico e inovador, ou competitivo e desviante. Entretanto, há duas características que parecem marcar os memoriais do IB: o tom humorístico e ainda a presença exacerbada do fazer coletivo. O humor confere ao éthos do biocientista certa leveza, até mesmo alguma descontração, enquanto a recorrência de figuras que remetem ao trabalho em equipe e do emprego do nós na sintaxe discursiva projetam um éthos cooperativo, algo que também está presente em muitos textos da FM, mas de modo atenuado.

Nota-se, dessa forma, que existem aspectos comuns, modos de dizer a memória ou ainda de fazer o trabalho da memória próprios à comunidade acadêmica, pois em todos os memoriais examinados aparecem o efeito de singularização do enunciador e essa preocupação em mostrar-se como um pesquisador competente, sério, objetivo, mas ao mesmo tempo dotado de certa sensibilidade. Os modos de produzir esse efeito de singularização, no entanto, são variados e revelam inclinações próprias a cada área, a cada instituto, faculdade, curso, e mesmo a cada texto examinado. Ao produzir suas memórias, o professor-pesquisador se produz, enquanto um modo de dizer e de ser, sempre entre o confronto e a conformidade com outras formas de habitar esse espaço de tensões que é a esfera acadêmica. 
BARROS, M. Memories of an academic course: an analysis of enunciantion's actor of academic autobiography. Alfa, São Paulo, v.65, 2021.

- ABSTRACT: The academic autobiography seems to be a privileged object for the examination of images and values concerning performance in the Brazilian academic environment. When the professor-researcher writes an academic autobiography, he draws up his professional and intellectual course as a reply to meet an institutional demand. A lot of academic contests at Brazilian universities ask applicants to write such a text genre. Taking this into consideration, the aim of this work is to analyze the production of enunciator-applicant's image. This work is based on Discini $(2003,2015)$ and Fiorin's $(2004,2015)$ proposals for the study of enunciator's actor within the Greimasian semiotics scope. By comparing texts of different areas and courses at the Universidade de São Paulo, we verify their differences and similarities in the uses of textual and discursive procedures for the construction of the enunciator's actor. As a result, we found the image of a bold, innovative, competitive and cooperative professor-researcher in the Biological memorials and of a critical, creative and slightly deviant professor-researcher in the Humanities memorials.

- KEYWORDS: academic autobiography; enunciation's actor; discursive semiotics.

\section{REFERÊNCIAS}

ANGYALOSSY, V. [Memorial]. Tese (Livre-Docência junto ao Departamento de Botânica) - Instituto de Biociências, Universidade de São Paulo, São Paulo, 2006.

AQUINO, J. G. Das coisas vivas: memorial de um professor. Tese (Concurso LivreDocência) - Faculdade de Educação, Universidade de São Paulo, São Paulo, 2009.

ARANTES, V. A. Memorial e curriculum vitae. Tese (Concurso de Livre-Docência) Faculdade de Educação, Universidade de São Paulo, São Paulo, 2012.

ARRIGUCCI Jr., D. [Memorial]. Tese (Concurso de Livre-Docência junto ao Departamento de Teoria Literária) - Faculdade de Filosofia, Letras e Ciências Humanas, Universidade de São Paulo, São Paulo, 1990.

BARROS, D. L. P. Teoria do discurso: fundamentos semióticos. São Paulo: Humanitas, 2002.

BARROS, M. L. P. As três identidades do discurso autobiográfico. CASA: Cadernos de Semiótica Aplicada, Araraquara, v. 10, n. 2, p. 1-20, 2012.

BENVENISTE, E. Problemas de linguística geral. Tradução de Maria da Glória Novak e Luiza Neri. Campinas: Pontes, 1995. Tomos I e II.

BOSI, E. Memória e sociedade: lembranças de velhos. São Paulo: Companhia das Letras, 1994. 
CARVAlHO, J. S. F. de. Memorial circunstanciado. Tese (Concurso de LivreDocência) - Faculdade de Educação, Universidade de São Paulo, São Paulo, 2013.

CHAUÍ-BERLINCK, J. G. [Memorial]. Tese (Livre-Docência junto ao Departamento de Fisiologia) - Instituto de Biociências, Universidade de São Paulo, 2006.

DISCINI, N. Corpo e estilo. São Paulo: Contexto, 2015.

DISCINI, N. O estilo nos textos. São Paulo: Contexto, 2003.

DISCINI, N. [Memorial]. Tese (Concurso para provimento de um cargo de Professor Doutor no Departamento de Linguística) - Faculdade de Filosofia, Letras e Ciências Humanas, Universidade de São Paulo, São Paulo, 2002.

FESTA NETO, C. [Memorial]. Tese (Concurso junto ao Departamento de Dermatologia) Faculdade de Medicina, Universidade de São Paulo, São Paulo, 2009. Sem paginação.

FIORIN, J. L. Argumentação. São Paulo: Contexto, 2015.

FIORIN, J. L. Semiótica e comunicação. Revista Galáxia, São Paulo, n. 18, p.13-30, 2004.

FIORIN, J. L. Linguagem e ideologia. São Paulo: Ática, 1998.

FIORIN, J. L. As astúcias da enunciação. São Paulo: Ática, 1996.

FIORIN, J. L. [Memorial]. Tese (Concurso de Livre-Docência junto ao Departamento de Linguística) - Faculdade de Filosofia, Letras e Ciências Humanas, Universidade de São Paulo, São Paulo, 1994.

GREIMAS, A. J.; COURTÉS, J. Dicionário de Semiótica. Tradução de Alceu Dias Lima et al. São Paulo: Contexto, 2008.

HALBWACHS, M. A Memória coletiva. Tradução de Laurent Léon Schaffter. São Paulo: Vértice; Revista dos Tribunais, 1990.

LATRONICO, A. C. [Memorial]. Tese (Concurso junto ao Departamento de Clínica Médica) - Faculdade de Medicina, Universidade de São Paulo, São Paulo, 2010.

LEJEUNE, P. Le pacte autobiographique. Paris: Seuil, 1996.

MAINGUENEAU, D. O contexto da obra literária. São Paulo: Martins Fontes, 1995.

MARANDINO, M. A construção de uma identidade profissional. Tese (Concurso de Livre-Docência) - Faculdade de Educação, Universidade de São Paulo, São Paulo, 2012.

MARQUES, F. P. de L. M. [Memorial]. Tese (Livre-Docência junto ao Departamento de Zoologia) - Instituto de Biociências, Universidade de São Paulo, São Paulo, 2007.

NEGRÃO, E. [Memorial]. Tese (Concurso para provimento de um cargo de Professor Titular no Departamento de Linguística) - Faculdade de Filosofia, Letras e Ciências Humanas, Universidade de São Paulo, São Paulo, 2004. 
NORONHA, I. de L. [Memorial]. Tese (Concurso junto ao Departamento de Clínica Médica) - Faculdade de Medicina, Universidade de São Paulo, São Paulo, 2010.

PETTER, M. M. T. [Memorial]. Tese (Concurso de Livre-Docência junto ao Departamento de Linguística) - Faculdade de Filosofia, Letras e Ciências Humanas, Universidade de São Paulo, São Paulo, 2008.

POMPÊO, M. L. M. [Memorial]. Tese (Concurso junto ao Departamento de Ecologia) Instituto de Biociências, Universidade de São Paulo, São Paulo, 2007.

QUADROS, M. [Memorial]. Tese (Concurso de Livre-Docência junto ao Departamento de Letras Clássicas e Vernáculas) - Faculdade de Filosofia, Letras e Ciências Humanas, Universidade de São Paulo, São Paulo, 2006.

SANTOS, M. F. dos. Forjas da temperança: caminhos de um Memorial. Tese (Concurso de Livre-Docência) - Faculdade de Educação, Universidade de São Paulo, São Paulo, 2003.

VIDAL, D. [Memorial]. Tese (Concurso de Livre-Docência) - Faculdade de Educação, Universidade de São Paulo, São Paulo, 2004.

ZILBERBERG, C. Eléments de grammaire tensive. Limoges: Pulim, 2006.

Recebido em 22 de janeiro de 2020

Aprovado em 5 de agosto de 2020 